\title{
ETHzürich
}

\section{Industry Diversity and Its Impact on the Innovation Performance of Firms: An Empirical Analysis Based on Firm-level Panel Data an empirical analysis based on firm-level panel data}

\section{Working Paper}

Author(s):

Wörter, Martin (1)

Publication date:

2007-05

Permanent link:

https://doi.org/10.3929/ethz-a-005390201

Rights / license:

In Copyright - Non-Commercial Use Permitted

Originally published in:

KOF Working Papers 165 


\section{KOF Working Papers}

Industry Diversity and Its Impact on the Innovation Performance of Firms

An Empirical Analysis Based on Firm-level Panel Data

Martin Wörter 


\section{KOF}

ETH Zurich

KOF Swiss Economic Institute WEH D 4

Weinbergstrasse 35

8092 Zurich

Switzerland

Phone +41446324239

Fax +41 446321218

www.kof.ethz.ch

kof@kof.ethz.ch 


\title{
Industry Diversity and Its Impact on the Innovation Performance of Firms*
}

- An Empirical Analysis Based on Firm-level Panel Data -

\author{
Martin Woerter \\ ETH Zurich, KOF Swiss Economic Institute \\ 8092 Zurich, Switzerland \\ Phone: +4144 / 632‘51'51 \\ Fax: +4144 / 632‘13‘52 \\ E-mail: woerter@kof.ethz.ch
}

\begin{abstract}
This paper investigates empirically the impact of diversity on the innovation performance of a firm. We created a measure for diversity that mirrors differences in the resource base of firms within an industry and tested its impact on innovation in addition to more traditional factors like technology-push, demand-pull, and firm-size, based on panel data stemming from three representative cross sectional surveys carried out in the years 1996, 1999, and 2002 respectively. In fact, diversity has a significant positive impact on the innovation intensity of firms and thus supports more theoretical findings in this area. We also find empirical evidence for the technology push and the demand pull hypotheses as well as the importance of competition for innovation.
\end{abstract}

Key words: Diversity, Innovation Performance, Evolution of Industries, Jacobs Externalities, Panel data,

JEL Classification: O30

\footnotetext{
*I would like to thank Nora Sydow for programming SAS macros in order to apply the measure of diversity. Many thanks also to Spyros Arvanitis, Heinz Hollenstein and the participants of the $\mathrm{KOF}$ research seminar for their valuable comments on the paper.
} 


\section{Introduction}

Economically modern and well developed societies heavily rely on the willingness and abilities of firms to innovate for at least two reasons: Firstly, in a so-called "globalised" economy Europe needs to strengthen its innovativeness to remain competitive in the future in order to maintain employment and secure social peace. Secondly, societies are increasingly confronted with unexpected adverse consequences of the behaviour of economic agents (e.g. environmental pollution, greenhouse effect, scarcity of natural resources). Therefore the innovation potential of firms is important to provide timely adequate solutions to these urgent problems. This is a necessary condition for the evolution of the economic system, since evolution means to solve the current problems (see Nelson 1995). And following the notion of competition within a Darwinian evolutionary model what matters is the joint distribution of relevant differences in innovative behaviour across firms. These differences are the necessary background upon which competitive selection takes place and on that the process of evolution depends (see Metcalfe and Miles 1994).

This investigation is motivated by the quest for better market circumstances in order to promote the innovation behaviour of firms and thus to increase the likelihood of economic evolution, i.e. to find timely solutions to unexpected adverse results of well-planned actions. It aims at analysing the main determinants of successful innovations of firms. In addition to the more traditional determinants that focus on the Schumpeterian hypotheses, technology push factors and demand pull factors, an empirical measure for diversity of the market environment similar to some biological notions is formulated and empirically tested.

Following the investigations of Nelson and Winter (1982) it can be seen that economic evolution is driven by firm heterogeneity. Also Chiaromonte and Dosi (1993) showed through simulations that more identical agents lead to very little technical progress and long-term fall in aggregate income. Thus, it is assumed that a more diverse market environment fosters the innovation performance of firms in the respective market.

In fact, our empirical findings are in line with the just mentioned investigations. Based on a comprehensive panel dataset, statistically representative for Switzerland, comprising 3 cross sections $(1996,1999,2002)$, it was found that 
firms embedded in a more diverse market environment have a better innovation performance than firms in more homogeneous markets.

What are some implications of these findings? Firstly, and a more theoretical implication is that the results show that micro-investigations of firms innovative behaviour that rely on the concept of "representative agents" maybe to some extent misleading, since it is heterogeneity in behaviour rather than uniformity that provides incentives for innovation as well (see Chiaromonte, Dosi 1993). Secondly, and a more policy related implication is that more diverse markets facilitate market entry and thus promote competition, since entrants are likely to find some particular, new product niche that may challenge the markets of incumbents in a longer run (see Feldman, Audretsch 1999, Jacobs 1969).

This paper is organised as follows. In chapter two the modelling framework is introduces. In chapter three we focus on diversity measures and define diversity for the purpose of this paper. In chapter four data are described and in chapter five we specify our empirical model based on the theoretical framework in chapter two. Chapter six shows the empirical results and in chapter seven we summarise the results and derive some conclusions. 


\section{Modelling framework}

\subsection{Determinants of innovative behaviour revisited}

The empirical investigation of what promotes innovative behaviour of firms mainly circulates around the following hypotheses: A) the so-called Schumpeterian hypotheses focuses on the meaning of firm size and market concentration on firms' innovative behaviour (see Cohen 1995, Cohen and Levin 1989). B) The demand-pull theses (see Schmookler 1966) emphasises that market conditions, size of the market and price development are very important. C) The technology-push hypotheses (see Phillips 1966, Rosenberg 1976) states that supply factors related to the conditions for knowledge production are essential. D) Furthermore there are several hypotheses circulating around the importance of financial restrictions (see Nelson 1959), R\&D risks and risk preferences of firms (see Mansfield 1968). E) Dosi (1988) essentially enhanced the empirical view on essential factors for innovative behaviour, by pointing at the importance of appropriability, partial tacitness, and variety of knowledge bases, uncertainty and technical opportunities.

These hypotheses were operationalised in different ways and empirical tested in a number of investigations (see Cohen 1995). As to investigations based on CIS (Community Innovation Survey) or SIS (Swiss Innovation Survey) ${ }^{1}$ the following empirical evidence can be derived. Arvanitis and Hollenstein (1996) found that demand-pull factors (to a weaker extent), but primarily supply-side factors (appropriability, technological opportunities) drive the innovation performance of Swiss manufacturing firms. Also larger firms (with more than 200 employees) have a greater propensity to innovation than smaller ones. Raymond et al. (2004) found in the Dutch case (three waves of the Dutch Community Innovation Survey, i.e. CIS 2, 2.5, 3) that demand-pull factors are more important than technologypush factors as to the innovation output measure (share of innovative sales). The size effect is in this case negative. This is in line with the findings of Mairesse and Mohnen (2001), with the exemption of a positive size effect and the positive correlation with demand-pull factors that is restricted to low-tech firms. Janz et al.

\footnotetext{
${ }^{1}$ The SIS is very similar to the CIS.
} 
(2003) found also a negative size effect (for Germany) but no demand-pull or technology-push effect. In contrast Crepon et al. (1998) do not detected any size effect but positive demand-pull or technology-push effects. All these studies are based on data derived form the CIS for manufacturing firms. In sum, there is no clear empirical evidence for positive size effects. As to technology-push and demand-pull effects one can see that they are significantly positive or not significantly related to the innovation performance of a firm. There has been never a negative sign detected.

\subsection{Bounded rationality of firm behaviour}

We intend to add a further perspective to this discussion about important driving factors for innovation. Following Dosi (1988) at least to some extent we want to put forward the hypotheses that not only the existence of single factors emphasised by investigations so far but also their diversity (or asymmetry) is relevant to innovative behaviour. Why does this proposition make sense? Why, for example, a "diverse" industry could be a more beneficial environment for innovations than a more homogeneous one?

The work of Nelson and Winter (1982) is an adequate starting point for analysing the possible impact of diversity on the innovation behaviour of firms. They put forward that economic evolution is driven by agents that are confronted with bounded rationality and uncertain circumstances. Furthermore agents dispose of different resources, like technological competencies and knowledge, as a result of their past decisions and experiences. Based on these resources they try to reduce existing complexity and uncertainty through routines (see Nelson 1995). Routines result from successful behaviours in the past, from the successful combination of firm resources. They symbolise goal-oriented learning and selection and thus, applied routines are the best available procedure from the perspective of the firm. You can find routines in several fields, e.g. in production (certain combination of input factors), organisational circumstances and applied technologies suggest a specific routine behaviour. Furthermore routines are established through organisational measures, e.g. the way the $R \& D$ department is integrated into firm's organisation. But what causes routines and how they can be changed? Learning is one driving force for modifying routines or firms may also investigate the adequacy of their routines through dedicated projects. 
However, short-term learning is limited and routines are bounded, e.g. according to the "satisfying" principle of Simon (1956) and they are very seldom fundamentally questioned and remain unchanged even if the economic environment may suggest a quite different behaviour (see Simon 1981). Furthermore firm's knowledge base, its technology and learning abilities are also very often bounded to prevailing paradigms (see Dosi 1988) or focused on a dominant design (see Utterback 1996) and thus limiting firms abilities to react upon or adapt to new market circumstances. A further restriction to unbiased perception of the economic environment and an argument for "path dependency" of behaviour can be found in the personal rule dependent perception as it is analysed in Holland et al. (1986). This way, important environmental signals, pointing at a change in behaviour, maybe overseen or simply ignored, since they are not foreseen in the rule code of the firm and its staff.

Acknowledging that firms reduce economic complexity through routines and that routines are bounded, it is clear that firms' develop their own, individual understanding of what characterises an efficient behaviour. Thus, firms distinguish themselves from competitors through working routines and based on these routines they decide what seems to be important for the firms' innovation behaviour and what negligible information out of the perceived economic environment is. Certainly, routines are far from being perfect in a way that they succeed in comprising all basically available information and reduce it to efficient working procedures. In general they cover only a section of available information. Imagine that newer knowledge is produced by other economic actors and this knowledge spreads in the market in form of a new technology. Some firms immediately may see the importance or this technology for future production. Other firms may also know about it but cannot detect any use. And a third category of firms may even not perceive or process this information. In contrast they may be busy with processing other information that in turn seems to be of no relevance for other firms (potential competitors). The point we want to make here is that based on their routines firms differ in their perception of what seems to be important for innovation behaviour. Based on their routines firms' differ in their problem perception and in their innovation behaviour. Thus we may conclude that a more divers sector ignores less and perceives more as a possible field for innovation and that increases the likelihood of innovations. 
Understanding that firms behaviour is based on routines that in turn are characterised by bounded rationality and that routines strongly differ between firms one can link it with the selection mechanism of competitive markets. Markets may select firms with adequate routines. Certainly other firms may learn to adapt their routines to meet changing market requirements, but they may be a second, in case that there are other firms operating on working routines, technologies etc. that better fit with the already changed market conditions. ${ }^{2}$ Thus learning may help to stay in the market but most probably with competitive disadvantages compared to firms with a better "fit". Putting it the other way one may see that diversity thus fasten the adaptiveness of an economy to changing market requirements or changing demand, since there is a higher probability that there are already firms that can rather immediately comply with the changed circumstances, e.g. they invested in the right technology, have an adequate firm size to produce efficiently, or they do research in niche markets that are, caused by the change of market circumstances, now more important. This means that their routines were less adequate in previous periods and they fit better now. Although usually longer lasting learning processes will take place and more and more firms may adapt successfully to the newer market requirements, the new circumstances will be addressed immediately and more efficiently by already "fitting" firms. This fastens market adaptability to changing societal needs or challenges and following Nelson (1995) this characterises the evolution of markets.

\subsection{The role of diversity for innovative behaviour: some theoretical aspects}

There are theoretical investigations on the impact of diversity of behaviour on technological change showing that based on a diffusion model, diversity is a necessary condition for the adoption of new technology. More clearly, Silverberg et al. 1988 stated that the overall diffusion process of a new technology is shaped by heterogeneous or diverse firm characteristics as to e.g. firm sizes or skill levels. Thus, the likelihood to adopt a new technology depends on the skill level of the

\footnotetext{
${ }^{2}$ Utterback (1996) describes the history of companies that were unable to change their innovation behavior, since they stuck to their "sunk" investments and technologies, although newer (better) technologies were already on the market.
} 
adopting firm and the level of skills generally available even to those firms not yet deploying the new technology. In turn the model indicates that the diffusion process in turn shapes firm characteristics. As a consequence new technologies or innovations seem to have an impact on diverse firm characteristics and those in turn, impact the diffusion process.

Also Chiaromonte and Dosi (1993) stated in a theoretical model framework that firm specific decision rules, together with firms' history of innovation, imitation and learning by individual actors is responsible for a permanent diversity among them. In fact, simulation results show that diversity among actors and as a consequence diverse economic behaviour has a positive effect on the rate of innovation.

Llerena and Oltra (2002) created a model in order to investigate several aspects of diverse innovation strategies of firms. Innovation strategies are fixed rules reflecting bounded rationality and refer to the learning process of a firm. They distinguish cumulative (relying on internal knowledge) from non-cumulative firms (learning process is external) or strategies and they saw that diversity of innovation strategies is a source of good technological performance and leads to higher productivity levels compared to industries with homogeneous strategies. This means that in the diverse case the available technological spectrum is better used and it is also shown that if we assume that strategies or different learning procedures are based on asymmetries in firm characteristics we find some theoretical hint that industry diversity is an important condition for technological change or innovation.

\subsection{The role of diversity for innovative behaviour: empirical evidence}

Based on existing, comprehensive empirical investigations, essentially Jacobs (1969) externalities may be seen as an empirical operationalisation of diversity that is close to our conceptual framework. Jacobs (1969) found that variety or diversity of industries promotes innovation and growth. Thus, a diverse knowledge environment, rather than similar knowledge and behaviour of economic actors foster creativity, promotes market entry and competition for new ideas and as a consequence intensifies innovative behaviour. Glaeser et al. (1992) largely confirmed the results of Jacobs, when they found that industries grow faster in cities with - relative to the national level - smaller firm size in that 
industry and city-industries grow faster when the rest of the city is less specialized. Thus, a more heterogeneous industry structure as to firm size distribution fosters growth. Only per implication one might assume that similar is true for the innovation performance.

Henderson et al. (1995) found empirical evidence for Jacobs's externalities only in the case of high-tech industries. Feldman and Audretsch (1999) link diversity of economic activity to innovation output and found support for the diversity thesis in line with the Jacobs model. Also Greunz (2004) stated that the composition of industrial activity influences the innovation performance of the manufacturing sector taking into account 153 European regions and 16 manufacturing sectors. European region's patent activities are also affected by Jacobs's externalities. Some of these studies also found empirical evidence for MAR externalities. This concept is the contra hypotheses to Jacobs's externalities. MAR (Marshall-Arrow-Romer) externalities mainly state that concentration rather than diversity promotes knowledge flows (spillovers) between firms and thus has a positive impact on the innovation performance of firms. Henderson et al. (1995) in the case of mature capital goods industries and Greunz (2004) as to European region's patent activities, found some empirical evidence for MAR externalities as well.

Considering our modelling framework and recognising that innovation is driven by problem perception and that problem perception depends on working routines that in turn are influenced by certain firm characteristics like firm size, physical capital or R\&D activities, then one can argue that industries with more diverse firm characteristics would be relatively more innovative than industries with rather homogeneous ones. Based on this hypotheses we investigate empirically based on a comprehensive data set (based on panel firm-level data), the impact of diversity on the innovation performance of firms. As just mentioned there are empirical investigations on an industry-level contrasting the impact of specialisation and diversity externalities on innovation performance. The study at hand differs from them in several respects. Firstly, diversity is measured quite differently, focusing on distance measures (asymmetries in firm structures) and thus enables us to test the above mentioned conceptual framework. This way it is tried to address some shortcomings of related papers as detected by Llerena and Oltra (2002). They stated that many theoretical and empirical works reveal the 
limits of a concept of diversity that only linked to the variety (multitude) of products or endowments. Secondly, we use panel firm-level data that allows us at least to some extent to address the "causality" question (innovation promotes diversity or vice versa). Thirdly, we have a number of control variables and variables addressing the more traditional hypotheses in addition to diversity.

\section{Measuring Diversity}

There are a number of different diversity measures. Most of them are inspired by physics and biology. In Sterling (1998) you will find a comprehensive overview of different measures of diversity. They will be not repeated here. Basically we want to focus on selected measures of importance for the formulation of the diversity measure applied in this investigation.

Our notion of measuring diversity is primarily inspired by biological diversity concepts. Nehring and Puppe (2002) propagate a multi-attribute approach in describing diversity. They isolated different attributes of species and point at dissimilarities in attributes. The smaller the probability to find a specific attribute of a species in the world the higher its value for the diversity. ${ }^{3}$

Nehring and Puppe (2002) formulate the following diversity function (V(S)):

$$
V(S)=\lambda(\{A \subseteq X: A \cap S \neq \varnothing\})=\sum_{A \subseteq X: A \cap S \neq \varnothing} \lambda_{A}
$$

In (1) the diversity of a set $\mathrm{S}$ is determined by frequency of attributes (A) possessed by the objects (species) in $\mathrm{S}$ ( $S \subseteq X ; \mathrm{X}$ is a finite universe of species). The function $\lambda: A \rightarrow \lambda_{A}$ indicates the attribute weighting function associated with V. $\lambda_{A}$ can be understood as the relative importance of the corresponding attribute (A). $\left\{A \subseteq X: \lambda_{A} \neq \varnothing\right\}$ is thought of the set of attributes with nonzero weight that will be called the group of relevant attributes. Thus, each single species

\footnotetext{
${ }^{3}$ Solow, Polasky and Broadus (1993) and M. Weitzman (1992, 1993) measured diversity based on genetic distances. They define the value of a species for the diversity of a subsample $\mathrm{S}$, according to their "genetic" distance to other species element of S. The genetic distances are measured, e.g. based on a taxonomic tree. Such a tree indicates the ancestors of a specific species and the time passed from its separation from this species. Thus the longer ago a species separated from another one, the greater is its "genetic" distance. This approach can be seen as a conceptual starting point for the Nehring and Puppe (2002) measure.
} 
contributes to diversity according to the weight of all those attributes that are not possessed by any already existing object. This criterion is very strict since it ignores how often certain attributes exist within a species. Certainly, the relative frequency of certain attributes may play an important role for the diversity as we will see later in the text when we focus on industries and firms and their different attributes.

Sterling $(1998,2004)$ introduced a measure of diversity considering variety, balance and disparity of "subsystems". Furthermore he integrated the different parts in a multi-criteria diversity index (M).

$M=\sum_{i j} d_{i j} p_{i} p_{j} \quad i \neq j$

In (2) diversity is measured by the sum of weighted "distances" or dissimilarities between different objects (e.g. portfolios, technologies). Dissimilarities or distances are indicated through $d_{i j}$ and the two weights are shown as $p_{i}$ (relative number of characteristic i) and $p_{j}$ (relative number of characteristic $\mathrm{j}$ ). Intuitively one can see that $\sum_{i j}$ covers the variety component, $d_{i j}$ symbolises the disparity component and $p_{i}$ and $p_{j}$ are indicating the balance of the two characteristics. The latter is rather important in economic terms, since a high incidence of certain characteristics initiates competition and as a consequence promotes the evolution of the economic system.

For the purpose of the empirical test at hand on the impact of diversity on innovation performance we refer to the two approaches. From Nehring and Puppe (2002) we learn that unique attributes are important rather than elements (whole entities). From Sterling (1998) we learn that weights or frequencies according to structural conditions of elements (e.g. technologies) and dissimilarities between them are important as well. The two approaches have in common that they measure diversity based on dissimilarities.

Following Nehring and Puppe (2002) our measure of diversity focuses on dissimilarities of firm attributes. We think that dissimilarities in firm characteristics, like size, education level of the staff, export behaviour and R\&D intensity have important implications for firm behaviour and they are key to describe the diversity of industries. In contrast to Nehring and Puppe (2002) we do not think that in an economic context only unique attributes are of value for diversity. It is more likely that dissimilarities between the just mentioned firm 
attributes may hold responsible for routines and innovative behaviour. Thus we apply a distance measure in measuring diversity of an industry, i.e. a simple Euclidean distance measure:

$$
\operatorname{DIV}(S)=\sum_{j=1}^{m} \sqrt{\sum_{i=1}^{n}\left(X_{i}-Y_{i}\right)^{2}} \quad i \neq j
$$

Following (3) the diversity (DIV) of industry (S) is the sum of the Euclidean distance of all possible pairs $(\mathrm{j}=1 \ldots \ldots . \mathrm{m})$ of firms $(\mathrm{X}, \mathrm{Y})$ based on their resource base $(\mathrm{i}=1 \ldots . .4) .{ }^{4}$ Thus we calculate the Euclidean distances between dissimilar firm attributes of all possible pairs of firms within an industry. In order to imagine our distance measure graphically, we assume to have only three firm attributes (\#1, \#2, \#3) and we have only three firms $(a, b, c)$ in an industry. Thus one can image the diversity of this industry as shown in figure 1 . The three firms are positioned according to their values for their three attributes respectively. The greater the distances between the firms in the 3 dimensional space, the greater their dissimilarity and the greater industries' diversity.

\section{Insert Figure 1}

In our empirical case we measure diversity as to four different firm attributes, i.e. firm size, share of exports on total sales, share of R\&D expenditures on total sales, and share of higher educated staff. These four attributes were chosen, since it is assumed that they have an influence on firms' behaviour in the market, on the way they "routinise" their work, and the way they perceive relevant problems in the environment. In order to measure the Euclidean distances these four variables have been standardised with mean 0 and standard deviation of $1 .{ }^{5}$

Table 1 shows some descriptive analysis of the diversity measure. It contains the degree of diversity for each industry in every single cross section and the aggregated degree of diversity by industry as an average of all three cross

\footnotetext{
${ }^{4} \mathrm{X}_{\mathrm{i}}=$ value in line $\mathrm{i}$ of firm vector $\mathrm{X}$; $\mathrm{Y}_{\mathrm{i}}=$ value in line $\mathrm{i}$ of firm vector $\mathrm{Y}$.

${ }^{5}$ Standardisation was conducted using SAS software according to the following formula: $x_{i}=\frac{S^{*}\left(x_{i}{ }^{\prime}-\bar{X}\right)}{S_{x}}+M$; while $x_{i}$ is the new standardised value, $\mathrm{S}$ is the chosen standard deviation value, $\mathrm{M}$ is the mean value, $S_{x}$ is the variables standard deviation, $x_{i}{ }^{\prime}$ is the observation's value, and $\bar{X}$ is the variables mean.
} 
sections. It is worth noticing that high-tech industries and modern service industries have a greater diversity than low-tech or traditional service industries. However there are some exceptions. Metal working and food/beverages also show a rather great diversity measure. Also wholesale and retail sale are very diverse according to our measure. Following our assumption that diversity fosters innovation, it is indicated that these industries have a greater potential for innovation than it is currently realised, of course differences in the technological potential of those industries have to be considered.

Insert Table 1

\section{Data}

Our empirical investigation about the impact of diversity on the innovation performance of a firm is based on panel data covering three cross-sections, i.e. 1996, 1999 and 2002. The data were collected in the course of three postal surveys using a rather comprehensive questionnaire, which included questions on firm characteristics, the market environment, innovation activities, R\&D activities and IPR (Intellectual Property Rights). The surveys were based on a (with respect to firm size) disproportionately stratified random sample of firms with at least 5 employees covering all relevant industries of the manufacturing sector, the construction sector and the service industry as well as firm size classes (on the whole 27 industries and within each industry three industry-specific firm size classes with full coverage of the upper class of large firms).

Table 2 provides us with an overview of the different surveys. We received answers from 1537 firms (response rate: $33.5 \%{ }^{6}$ ), 1470 firms (33.8\%) and 1938 firms (39.6\%) for the years 1996, 1999, 2002 respectively. In sum the firm panel covers 4945 observations. Because of item non-response, and some conflicting, non-plausible answers, 4050 observations could have been used for econometric estimations. Since our investigation only focuses on innovative firms, the panel estimation (see Table 5) is based on 2539 observations. 


\section{Hypotheses and model specification}

Following the modelling framework in chapter two and taking into account data restrictions, it is possible to specify the following model:

$y_{i t}=\beta_{0}+\beta_{1} H E D U+\beta_{2} C I N T+\beta_{3} D+\beta_{4} T P O T+\beta_{5} C O N C+\beta_{6} I P C+\beta_{7} I N P C+\beta_{8} D I V(f a)+$ $+\beta_{9} S I Z E+\beta_{10} S E C+\beta_{11 T D U M}+e_{i t}$

Our dependent variable $\left(y_{i t}\right)$ represents the innovation performance of a firm and it is measured through the share of innovative products on total sales (see Table 3). $i$ represents the number of firms and $t$ indicates the years 1996, 1999 or 2002.

Insert Table 3

The vector of independent variables (see Table 4) consists of variables representing the resource base of a firm. HEDU (Share of employees with higher education) represents the human capital of a firm. It is assumed to have a positive impact on the innovation performance. Also the second variable representing the resource base of a firm, the physical capital intensity (CINT), is likely to show a significant positive impact on the dependent variable.

\section{Insert Table 4}

Demand pull effects are indicated by the variable $\mathrm{D}$ that is measured through the medium-term expected change of demand as it is perceived by the respondents of our questionnaires. It is assumed that demand pull effects have a positive impact on the innovation performance of the firm. The same is true for TPOT. This

\footnotetext{
${ }^{6}$ This figure represents the response rate for the manufacturing sector. The response rate for the service sector and the construction sector amounts to $31.6 \%$. The respective figures for 1999 and 2002 cover the all three sectors.
} 
variable proxies the general technological potential relevant to the firm's innovation activity and it represents technology push effects. Firms with greater technological potentials should be more innovative than others.

The competitive environment is assumed to have a significant impact on the innovation performance of firms as well. We apply two different measures for competition. The first is a concentration measure that is based on the number of principal competitors in the world (product) market. There are 5 dummy variables, i.e. less than 5 competitors, between 5 and 10 competitors, between 11 and 15 competitors, between 16 and 50 competitors and more than 50 competitors (reference). It is assumed that more competitors intensify competition and thus promote innovative behaviour. There are two further variables that characterise the competitive environment as well. IPC informs us about the intensity of price competition in the product market. INPC tells about the intensity of non-price competition in the product market measured through the importance of several non-price competition dimensions, e.g. quality based competition, customization, range of goods, technology advance, service, design. Respondents were asked to assess the importance of such items on a five point Likert-scale ( 1 means less important for competition, 5 means very important for competition). In order to build INPC we summed up the scores and divided it through the number of nonprice competition dimensions. For both, IPC and INPC, a positive impact on the innovation performance of a firm is expected.

Diversity is measured according to expression (3) focusing on the resource base of a firm, i.e. human capital, knowledge capital, international market experiences and firm size. Dissimilarities in these factors are hold responsible for different firm routines and different perception of the economic environment. In general it is hypothesised that firms embedded in a more diverse industry have a better innovation performance than firms embedded in less diverse industry environments. There are two variables for diversity of an industry. DIV measures the sum of Euclidean distances (logarithm) and DIV(fa) shows the average contribution of a firm to industries' diversity by dividing DIV through the number of firms affiliated to an industry. In the paper at hand we only present the estimation with DIV(fa). However, DIV also has a positive impact on the dependent variable. 
There are a number of control variables in the estimation. We built 7 size dummies (SIZE: G1 to G7), whereas firms with less than 20 employees (G1) are the reference group. Furthermore there are 5 sector dummies (SEC) referring to firms affiliated to the high-tech manufacturing sector (HTCH), to firms affiliated to the low-tech manufacturing sector (LTCH), the construction sector (CONSTR), the modern service sector (MDL) and the traditional service sector (TDL). Firms in the construction sector act as a reference in the estimation. Three time-dummies (TDUM) refer to the cross-sections 1996 (DUM96), 1999 (DUM99) and 2002 (DUM02) respectively. DUM96 is the reference.

\section{Estimation results and the impact of diversity on innovation performance}

Table 5 shows the results of our panel estimation. The random effect tobit procedure was found to be an efficient estimator for several reasons. Firstly, our dependent variable (INPD) is very right skewed. Secondly, there is a possibility of a selectivity bias since not all of the responding panel-firms do have innovations. A Heckman procedure (see Heckman 1976) was applied to detect the possible bias. In fact no selection bias has been detected. The chi2 test on the correlation of the two error-components (for selection specification and for intensity specification) was not significant (Wald test of independent equations (rho $=0$ ): $\operatorname{chi} 2(1)=1.27 ;$ prob. $>$ chi2 $=0.2602)$. Thirdly, Heteroskedasticity and autocorrelation are two more possible sources of inefficient panel estimations. As to heteroskedasticity we carried out a likelihood-ratio test comparing GLS (General least squares) estimates under the assumption of heteroskedasticity with GLS estimates under the assumption of homoskedasticity ${ }^{7}$. The likelihood-ratio test assumes that the homoskedastic estimates are nested in the heteroskedastic ones. The result showed no significant heteroskedastic bias (prob. $>$ chi2 $=$ 0.0014). In order to investigate a possible autocorrelation bias, the Wooldridge test for autocorrelation in panel data was applied (see Wooldrige 2002, p. 282283) using STATA software; no significant serial correlation could have been

\footnotetext{
${ }^{7}$ In order to carry out this calculation we used the STATA software.
} 
detected (H0: no first-order autocorrelation, prob. $>\mathrm{F}=0.2135) .{ }^{8}$ Fourthly, the results are also not affected by multicollinearity (see correlations in table A.1).

\section{Insert Table 5}

We tested the main hypotheses put forward by the innovation literature on the most important drivers for innovation activities in firms. Technology push as well as the demand pull effects are significantly positively correlated with the innovation intensity of a firm. Both variables, D and TPOT for the demand pull and technology push effect respectively, show a significant positive sign. These results for Switzerland (including manufacturing, construction and services) are in line with the investigations on the manufacturing sector in France (see Crépon et al. 1998) in Netherlands (see Brouwer, Kleinknecht 1996) and in Ireland (see Mohnen, Dagenais 2001) as to the demand pull effect. Also Raymond et al. (2004) saw again for Netherlands a significant positive impact of demand pull effects on the innovation performance of manufacturing firms. However the variable for technology push does not show any effect.

As expected the resource base of a firm is very important for their innovation activities. We see that the variables for human capital (HEDU) as well as physical capital (CINT) have a significant positive impact on the share of innovative products on total sales (INPD). Also the competitive environment has an impact on the innovation performance of firms. The intensity of non-price competition fosters innovations while price competition does not show any significant impact. The number of principal competitors has a rather weak impact on the innovation performance. Only one dummy (CONC11-15) shows a significant impact compared to CONC50 (as reference). This indicates that more oligopolistic-like market circumstances, where the number of competitors is manageable, are more conducive for innovation than polypolistic-like market circumstances (more than 50 principal competitors). However, variables representing less than 5 competitors (CONC5) or between 5 and 10 competitors (CONC5-10) do not differ significantly from the reference variable, implicating that there is no clear

\footnotetext{
${ }^{8}$ The Heckman estimation, the test for heteroskedasticity and autocorrelation are not presented in the paper.
} 
tendency towards a positive impact of fewer market participants on innovation activities.

The variable for diversity (DIV(fa)) shows a significant positive impact on the innovation intensity of a firm. Thus, the hypotheses is supported that firms in more diverse industries show a relatively better innovation performance than firms in less diverse ones. Thus, we can empirically confirm the findings of Chiaromonte and Dosi (1993), Silverberg et al. (1998) and Llerena and Oltra (2002) that more diverse economic behaviour or asymmetric firm structures indicate a better innovation or technological performance. Following this it could be at least to some extent misleading to analyse drivers of innovation based on representative homogeneous agents. Rather than homogeneity it is their diversity that drives innovation and technology. In addition to this more conceptual implication, there are some policy-making as well.

One can ask how diversity in industries can be promoted. Certainly, competition authorities are of great importance in watching the contestability of the respective markets. Many innovations are stemming from new, very often small entrant firms. They discover economic niches and successfully fill them or they may serve larger, incumbent firms with specialised products that enable them to be innovative as well. Contestable markets and diversity may positively interact in order to increase market flexibility to react upon new challenges and make innovations more likely. This way, diversity is a possible indicator for market contestability.

Innovation policy measures should not only focus on certain types of firms, more important are differences in approaches or subjects. This way innovation policy remains neutral as at to firm heterogeneity in industries or even supports it. Diversity would be promoted if innovation policy causes some behavioural additionality, i.e. a firm carries out a research project that would have been drop down without public support. However such investigations must be left for future research and they cannot be done within the framework of the study at hand.

Causality between the measure for diversity and the dependent variable could be a further interesting topic. It was not possible to control for simultaneity between these two variables, since we are lacking a theory of what determines the diversity of industries and thus only a very ad-hoc specification of diversity would have been possible. We abandoned to do so in this study. The quest for determinants 
for diversity should be left for future research. However it was possible to lag the diversity variable (estimation not shown in this paper) and it was found that the significant positive relation with the dependent variable remained stable indicating that causality runs from diversity to innovation (lag three years). Certainly the contrary is also possible although with perhaps different lag structures.

Firm size does not play any significant role. Our size dummies do not differ significantly from the reference size (less than 20 employees). This result is in line with the investigations from Crépon et al. (1998) and Mohnen, Dagenais (2001). Further control variables for sector affiliation (HTCH, LTCH, MDL, TDL) and cross-sections (DUM99, DUM02) respectively are significant. Firms affiliated to the construction sector are significantly less innovative than firms affiliated to the high-tech, low-tech, modern services or traditional service sector. The crosssection dummies mirror the overall innovation performance of Swiss firms. Comparing the years 1996, 1999 and 2002 Swiss firms loose some innovative power due to - at least to some extent - rather poor overall economic development. Thus, it is not surprising that both applied cross-section dummies show a significant negative sign (reference DUM96).

\section{Summary and Conclusions}

Diversity is seen as the main driving force for evolution. In order to empirically test the impact of diversity on the innovation performance of a firm we mainly refer to the work of Nelson and Winter (1982) stating that economic evolution is driven by agents that are confronted with bounded rationality and uncertain circumstances. Furthermore Nelson (1995) emphasised the importance of routines to reduce complexity. Acknowledging that routines are determined by the resource base of a firm, we develop a diversity measure that measures the differences in the resource base of firms and thus enables us to test whether this kind of diversity (diversity in resources and in working routines) has a positive impact on the innovation intensity of a firm in addition to more traditional important drivers of innovation, e.g. technology-push, demand-pull, and firm size. Based on a comprehensive panel data covering three cross-sections (1996, 1999, 2002) it was found that diversity has a significant positive impact on the innovation performance (intensity) of a firm. Thus we can empirically confirm the 
more theoretical investigations on diversity and innovation or technological change (see Silverberg et al. 1988, Chiaromonte and Dosi 1993 or Llerena and Oltra 2002) and it becomes empirically obviously that differences in economic agents (firms) promote innovative behaviour.

This result has several implications for economic innovation research and policy making. It put some doubts on the usefulness of "representative agents" in order to model innovative behaviour of firms. We saw that rather than their homogeneity it is their diversity that promotes innovative behaviour.

Industry diversity may be also a challenge for national competition authorities. A competitive environment that is characterised through firm diversity promotes innovations and following Jacobs (1969) conclusions, it facilitates the entry of new firms that maybe specialised in some particular, new, product niches. Following the contestable market theory, markets should be open for new qualified entry that in turn promote diversity of industries and vice versa.

Industry diversity may be also a challenge for innovation policy. It could contribute to increase or decrease industry diversity and thus to multiply its likely positive effect on the innovation performance of firms, by not only promoting innovative behaviour directly, but contributing to a diverse research environment. Thus, their policy measures should be neutral as to firm heterogeneity in industries or even promotes it. Diversity would be promoted if innovation policy causes some behavioural additionality, i.e. a firm addresses an urgent problem through a research projects that would have been drop down (lacking resources) without public support.

Certainly one could argue that there can be too much of diversity at the cost of efficiency. Thus, to find a balance between efficiency and effectivity as it was questioned by March (1994) could be a future topic for investigation. Also to investigate empirically diversity and its relation to productivity or its meaning for technological diffusion as well as a more detailed investigation of the "causality" question must be left for future empirical research. 


\section{References}

Arvanitis S Hollenstein H (1996) Industrial Innovation in Switzerland: A Model-based Analysis with Survey Data. in: Kleinknecht A (ed.) Determinants of Innovation, the Message From New Indicators. Macmillan Press Ltd, London: 13-62

Brouwer E Kleinknecht A (1996) Determinants of Innovation: A Micro Econometric Analysis of Three Alternative Innovative Output Indicators. In: Kleinknecht A (ed.) Determinants of Innovation, the Message From New Indicators. Macmillan Press Ltd, London: 99-124

Chiaromonte F Dosi G (1993) The Micro Foundations of Competitiveness and their Macroeconomic Implications. in: Foray D Freeman Ch (eds.) Technology and the Wealth of Nations. Pinter Publishers, London New York: 107-134

Crépon B Duguet E Mairesse J (1998) Research and Development, Innovation and Productivity: An Econometric Analysis at the Firm Level. Economics of Innovation and New Technology 7 (2): $115-158$

Cohen WM (1989) Empirical Studies of Innovative Activity. in: Stoneman P (ed.) Handbook of the Economics of Innovation and Technological Change. Blackwell, Oxford

Cohen WM Levin RC (1989) Empirical Studies of Innovation of market Structure. in: Schmalensee R Willig R (eds.) Handbook of Industrial Organization. North Holland, Amsterdam

Dosi G (1988) Sources, Procedures, and Microeconomic Effects of Innovation. Journal of Economic Literature 26 (September): 1120-1171

Feldman MP Audretsch DB (1999) Innovation in Cities: Science-based Diversity, Specialisation and Localized Competition. European Economic Review 43: 409-429

Glaeser E Kallal H Scheinkam J Shleifer A (1992) Growth in cities. The Journal of Political Economy 100: 1126-1152

Greunz L (2004) Industrial Structure and Innovation - Evidence from European Regions. Journal of Evolutionary Economics 14: 563-592. DOI: 10.1007/s00191-004-0234-8

Heckman JJ (1976) The Common Structure of Statistical Models of Truncation, Sample Selection, and Limited Dependent Variables and a Simple Estimator for Such Models. The Annals of Economic and Social Measurement 5: 475-492.

Henderson V Kuncoro A Turner M (1995) Industrial Development in Cities. Journal of Political Economy 103 (5): 1067-1090.

Holland JH Holyoak KJ Nisbett RR Thagard PE (1986) Induction - Processes of Inference, Learning, and Discovery. MIT, Boston

Jacobs J (1969) The Economy of Cities. Random House, New York

Janz N Lööf H Peters B (2003) Firm Level Innovation and Productivity - Is there a Common Story across Countries? Problems and Perspectives in Management 2: 1-22

Llerena P Oltra V (2002) Diversity of Innovative Strategy as a Source of Technological Performance. Structural Change and Economic Growth 13: 179-201

March JG (1994) Three Lectures on Efficiency and Adaptiveness in Organization. First Goran and Louise Ehrnrooth Lectures, Helsinki.

Mairesse J Mohnen P (2001) To be or not to be Innovative: an Exercise in Measurement. MERITInfonomics Research Memorandum series Nr. 2001-039, MERIT, Maastricht

Mansfield E (1968) The Economics of Technical Change. Norton \& Co, New York

Metcalfe JS Miles I (1994) Standards, Selection and Variety: an Evolutionary Approach. Information Economics and Policy 6: 243-268

Nehring K Puppe C (2002) A Theory of Diversity. Econometrica 70 (3): 1155-1198 
Nelson RR (1959) The Simple Economics of Basic Scientific Research. Journal of Political Economy 67: 297-306

Nelson RR (1995) Recent Evolutionary Theorizing About Economic Change. Journal of Economic Literature 33 (March): 48-90

Nelson RR Winter SG (1982) An Evolutionary Theory of Economic Change. Belknap Press of Harvard University Press, Cambridge.

Phillips A (1966) Patents, Competition, and Technical Progress. American Economic Review 56: 301-310

Raymond W Mohnen P Palm F Van der Loeff SS (2004) An Empirically-Based Taxonomy of Dutch Manufacturing: Innovation Policy Implications. MERIT-Infonomics Research Memorandum series 2004-011, MERIT, Maastricht

Rosenberg N (1976) Perspectives on Technology. Cambridge University Press, Cambridge.

Schmookler J (1966) Invention and Growth, Schumpeterian Perspectives. MIT Press, Cambridge, Mass

Silverberg G Dosi G Orsenigo L (1988) Innovation, Diversity and Diffusion: A Self-Organisation Model. The Economic Journal 98 (December): 1032-1054

Simon HA (1956) Rational Choice and the Structure of the Environment. in: Egidi M Marris R (1992) (eds.) Economics, Bounded Rationality and the Cognitive Revolution, Herbert Simon. Edward Elgar Publishing Limited, Aldershot, Brookfield

Simon HA (1981) Entscheidungsverhalten in Organisationen. Verlag Moderne Industrie

Sterling A (1998) On the Economics and Analysis of Diversity. SPRU Electronic Working Paper Series, Paper No. 28, October

Sterling A (2004) Diverse Design: Fostering Technological Diversity in Innovation for Sustainability. Paper Submitted to Colloquium DEA, Durham Business School and Cranfield School of Management on: The Role of Diversity in Social Systems and its Relation to Innovation. Bologna, 12-13 July

Solow A Polasky St Broadus J (1993) On the Measurement of Biological Diversity. Journal of Environmental Economics and Management 24: 60-68

Utterback JM (1996) Mastering the Dynamics of Innovation. Harvard Business School Press, Boston (Massachusetts)

Weitzman ML (1992) On Diversity. The Quarterly Journal of Economics 107 (2) May: 363-405

Weitzman ML (1993) What to Preserve? An Application of Diversity Theory to Crane Conservation. The Quarterly Journal of Economics 108 (1), February: 157-183

Wernerfelt B (1984). A Resource-based View of the Firm. Strategic Management Journal 5: 171180

Wooldridge JM (2002) Econometric analysis of Cross Section and Panel Data. The MIT Press, Cambridge (Massachusetts) London (England) 
Figure 1: Diversity: stylised in a 3 dimensional space

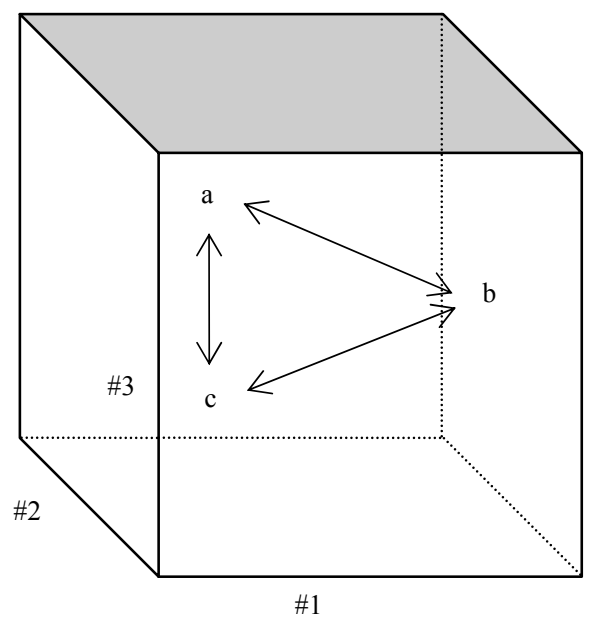


Table 1: Diversity measures for Industries (1996, 1999, 2002)

\begin{tabular}{|c|c|c|c|c|}
\hline & \multicolumn{4}{|c|}{$\operatorname{DIV}(\mathbf{f a}) * 100$} \\
\hline & $t(1-3)$ & t1 (1996) & t2 (1999) & t3 (2002) \\
\hline \multicolumn{5}{|l|}{ Manufacturing } \\
\hline Food/Beverage & 152.96 & 152.41 & 147.31 & 157.50 \\
\hline Textile & 145.01 & 148.91 & 139.57 & 145.96 \\
\hline Clothing/Leather & 96.54 & 97.17 & 108.67 & 76.36 \\
\hline Wood processing & 123.34 & 133.32 & 110.72 & 119.77 \\
\hline Paper & 112.77 & 106.11 & 101.50 & 123.98 \\
\hline Publishing & 142.31 & 125.90 & 147.76 & 150.26 \\
\hline Petroleum/Chemicals & 180.66 & 171.63 & 180.31 & 186.21 \\
\hline Rubber/Plastic product & 147.29 & 148.81 & 135.73 & 153.93 \\
\hline $\begin{array}{l}\text { Other non-metallic mineral } \\
\text { products }\end{array}$ & 126.07 & 125.23 & 124.46 & 128.27 \\
\hline Metal & 111.67 & 119.68 & 96.91 & 114.34 \\
\hline Metalworking & 196.73 & 199.93 & 184.39 & 202.07 \\
\hline Machinery & 214.81 & 203.15 & 214.03 & 223.08 \\
\hline Electrical machinery & 164.04 & 166.91 & 161.94 & 163.36 \\
\hline Electronic/Instruments & 204.17 & 198.32 & 197.01 & 213.07 \\
\hline Watches & 138.84 & 134.81 & 148.09 & 129.84 \\
\hline Vehicles & 125.74 & 133.92 & 101.45 & 132.63 \\
\hline Other Manufacturing & 135.33 & 134.82 & 116.77 & 148.95 \\
\hline Energy/Water & 112.54 & n.a. & 77.54 & 137.54 \\
\hline Construction & 172.82 & 165.36 & 181.92 & 170.92 \\
\hline \multicolumn{5}{|l|}{ Services } \\
\hline Wholesale & 187.07 & 170.52 & 189.18 & 197.46 \\
\hline Retail trade & 164.84 & 178.55 & 147.95 & 168.30 \\
\hline Hotels and restaurants & 127.53 & 129.00 & 125.57 & 127.32 \\
\hline Transport/Telecommunication & 154.50 & 132.68 & 161.76 & 157.26 \\
\hline Banking/Insurance & 148.72 & 118.90 & 141.13 & 163.46 \\
\hline Real estate / Renting & 52.77 & 52.40 & 22.17 & 71.50 \\
\hline Computer services & 183.09 & 198.37 & 170.96 & 173.85 \\
\hline Business services & 202.49 & 200.96 & 198.08 & 207.93 \\
\hline Personal services & 36.59 & 52.46 & -28.39 & 46.16 \\
\hline
\end{tabular}

Diversity (DIV(fa)) calculated according to formula (3) divided through the number of firms in the respective industry and multiplied with 100 . 
Table 2: Number of observations (1996, 1999, 2002)

\begin{tabular}{|c|c|c|c|c|}
\hline & \multicolumn{4}{|c|}{ Observations } \\
\hline & $t(1-3)$ & t1 (1996) & t2 (1999) & t3 (2002) \\
\hline Manufacturing & 2834 & 904 & 822 & 1108 \\
\hline Food/Beverage & 204 & 58 & 62 & 84 \\
\hline Textile & 102 & 32 & 30 & 40 \\
\hline Clothing/Leather & 42 & 19 & 14 & 9 \\
\hline Wood processing & 120 & 51 & 29 & 40 \\
\hline Paper & 72 & 20 & 20 & 32 \\
\hline Publishing & 186 & 55 & 56 & 75 \\
\hline Petroleum/Chemicals & 163 & 41 & 52 & 70 \\
\hline Rubber/Plastic product & 150 & 49 & 41 & 60 \\
\hline $\begin{array}{l}\text { Other non-metallic mineral } \\
\text { products }\end{array}$ & 122 & 43 & 36 & 43 \\
\hline Metal & 70 & 27 & 19 & 24 \\
\hline Metalworking & 430 & 164 & 110 & 156 \\
\hline Machinery & 448 & 124 & 136 & 188 \\
\hline Electrical machinery & 127 & 40 & 39 & 48 \\
\hline Electronic/Instruments & 262 & 83 & 69 & 110 \\
\hline Watches & 94 & 27 & 39 & 28 \\
\hline Vehicles & 59 & 23 & 14 & 22 \\
\hline Other Manufacturing & 123 & 48 & 31 & 44 \\
\hline Energy/Water & 60 & n.a. & 25 & 35 \\
\hline Construction & 486 & 156 & 163 & 167 \\
\hline Services & 1625 & 477 & 485 & 663 \\
\hline Wholesale & 395 & 113 & 128 & 154 \\
\hline Retail trade & 252 & 58 & 72 & 122 \\
\hline Hotels and restaurants & 168 & 61 & 38 & 69 \\
\hline Transport/Telecommunication & 202 & 37 & 78 & 87 \\
\hline Banking/Insurance & 115 & 20 & 36 & 59 \\
\hline Real estate / Renting & 26 & 10 & 6 & 10 \\
\hline Computer services & 106 & 43 & 26 & 37 \\
\hline Business services & 319 & 116 & 94 & 109 \\
\hline Personal services & 42 & 19 & 7 & 16 \\
\hline Total & 4945 & 1537 & 1470 & 1938 \\
\hline
\end{tabular}

Because of item non-response and some contradictions, non-plausible answers, 4050 observations could be taken into consideration in our estimations (see Table 5). Since firms affiliated to the "energy/water industry were not included in the survey 1999, we excluded them from the panelestimations. 
Table 3: Dependent variable

\begin{tabular}{l|l}
\hline Dependent Variable & Description \\
\hline INPD & $\begin{array}{l}\text { Logarithm of innovative products on total sales } \\
\text { for the years 1996, 1999, 2002 }\end{array}$ \\
\hline
\end{tabular}

Table 4: Determinants of firms' innovation performance - Independent variables

\begin{tabular}{l|lc}
\hline Independent Variables & Description & $\begin{array}{l}\text { Expected } \\
\text { sign }\end{array}$ \\
\hline
\end{tabular}

Resource base HEDU (Human Capital) Logarithm of the share of employees with tertiary-level vocational education
2005 (universities, universities of applied sciences, other business and technical schools at tertiary level)

CINT (Physical Capital) Logarithm of the share of value added and personnel costs on total sales

Demand (pull)

$\mathrm{D}$

Medium-term expected change in demand (on a five point Likert-scale; 1 strong decline, 5 strong increase)

\section{Technological opportunities (push)}

\section{TPOT}

\section{Competitive environment}

CONC

IPC

INPC

\section{Diversity (industry-level) \\ DIV}

\section{$\operatorname{DIV}(f a)$}

\section{Control variables}

SIZE (G1 to G7)

TDUM (DUM96, DUM99, DUM02)

SEC (HTCH, LTCH, CONSTR, MSER, TSER)
General technological potential, i.e. scientific and technological knowledge relevant to the firm's innovation activity (on a five point Likert-scale; 1 very low, 5 very high technological potential)

Concentration measure based on the number of principal competitors in the world (product) market (dummy variables: CONC5 = less than 5; CONC5-10 $=5$ to $10 ;$ CONC11-15 = 11 to $15 ;$ CONC16-50 = 16 to $50 ;$ CONC50 = more than 50 is the reference group)

Intensity of price competition in the product market

Intensity of non-price competition in the product market

Logarithm of the sum of Euclidean distances of differences in the resource base of firms affiliated to the same industry, i.e. differences in human capital, knowledge capital, international market experiences and firm size. Human capital is measured through share of employees with tertiary-level vocational education. Knowledge capital is measured through share of R\&D expenditures on total sales. International experiences are indicated through share of exports on total sales and number of employees (in full-time equivalents) is a proxy for firm size. In order to calculate the Euclidean distances all applied variables have been standardised with mean 0 and standard deviation of 1.

We divide the logarithm of the sum of Euclidean distances through the number of firms affiliated to an industry. Thus the average contribution of a firm to industries' diversity is indicated.

Seven size dummy variables (SIZE) based on number of employees (full-time equivalent); G1 (<20), G2 (20 - <50), G3 (50-<100), G4 (100 - <200), G5 $(200-<500), G 6(500-<1000)$, G7 $(1000+)$. Reference size dummy = G1 Three time-dummy variables (TDUM) for the cross-sections 1996, 1999 and 2002 respectively (DUM96 is the reference)

Five sector dummy variables (SEC) based on the sector affiliation of the firm; $\mathrm{HTCH}$ (high-tech firms; petroleum/chemicals, plastics/rubber, machinery electrical machinery, electronic/instruments, vehicles), LTCH (low-tech firms; food/beverage, textile, clothing/leather, wood processing, paper, publishing glass/stone/clay, metal, metal working, watches, other manufacturing, energy/ water); CONSTR (construction sector), MSER (modern services; banking/ insurance, computer services, business services) TSER (traditional services; wholesale, retail trade, hotels and restaurants, transport/telecommunication, real estate/renting, personnel services). Reference sector $=$ CONSTR 
Table 5: Estimation results

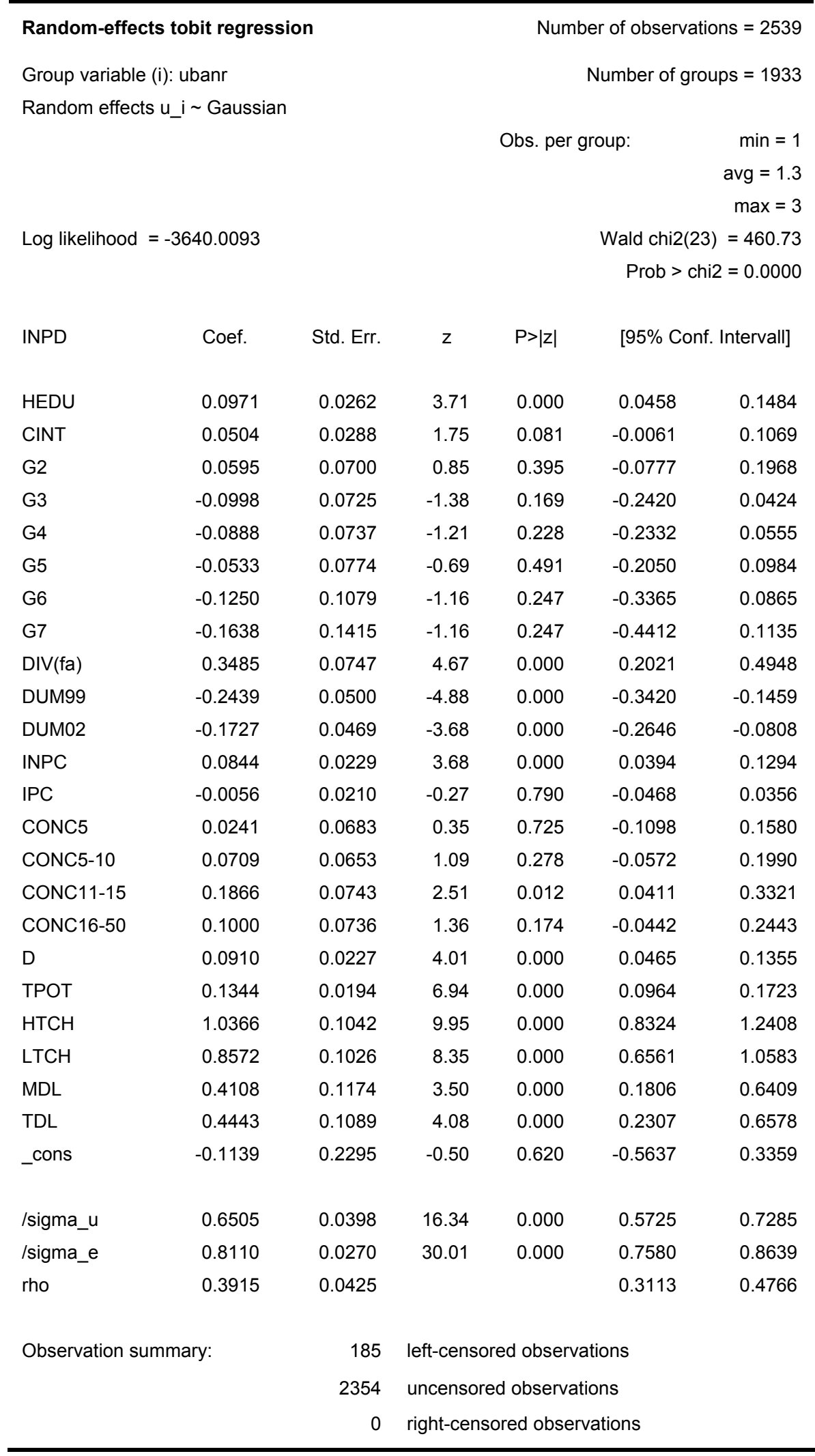




\section{Appendix}

Table A.1: Correlations between determinants

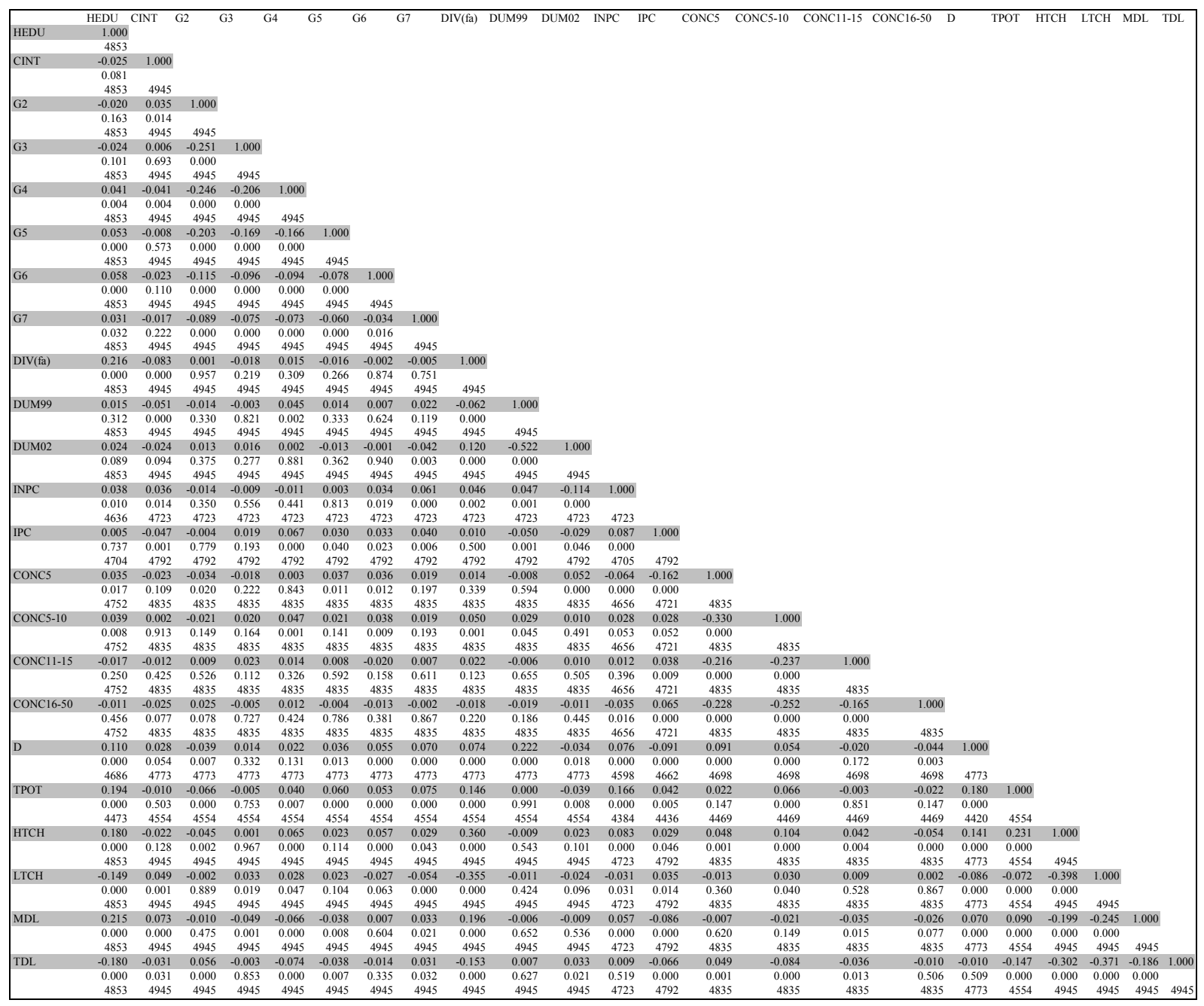

